http://dx.doi.org/10.30681/23588403v11i01188197

\title{
A ACEITAÇÃO ESTRATÉGICA DA RELIGIÃO DO OUTRO EM “O GUARANI" DE JOSÉ DE ALENCAR
}

\author{
Data de recebimento: $24 / 08 / 2017$
}

Aceite: 18/11/2017

Gustavo COSTA (Texas Tech University) ${ }^{1}$

Resumo: A formação da cultura brasileira é percebida em $O$ Guarani de José de Alencar através do ambiente e dos personagens presentes na obra. O personagem Peri não possui religião e sua língua materna é o tupi, aprende o português para se comunicar com a família de Dom Antônio de Mariz, sendo o português sua língua oficial. Por meio de textos relacionados à religião, observa-se a aceitação estratégica entre as diferenças relacionadas à fé encontrada na obra, sendo esta o catolicismo dos portugueses e o panteísmo do índio Peri, crença esta professada pelos indígenas, povos primitivos que não conheciam nenhum tipo de religião.

Palavras-chave: Religião. O Guarani. José de Alencar. Literatura Brasileira.

Abstract: The formation of Brazilian culture is perceived in $O$ Guarani by José de Alencar through the environment and the characters which are present in the title. Peri does not have any religion and his mother tongue is Tupi. He learns Portuguese to communicate with the family of Dom Antônio de Mariz, being portuguese his official language. Through religionrelated texts, it is observed the strategic "acceptance" of the differences related to the faith found in the work, which is the Catholicism of the Portuguese and the Indian pantheism of Peri, faith which is professed by the indigenous, primitive people who did not know any kind of religion.

Keywords: Religion; O Guarani. José de Alencar. Brazilian Literature

Esta gentilidade como não têm ídolos por quem morram, tudo quanto lhes dizem, crêem; a dificuldade está somente em tirar-lhes todos os seus maus costumes, mudando-os em outros bons, segundo Cristo (JOSÉ MARIA DE PAIVA, 2005, pp. 6-7 apud Nóbrega, 10.03.1553 LEITE, I, p. 452).

O Guarani é um romance brasileiro, escrito por José de Alencar, primeiramente publicado em formato de folhetim no Diário do Rio de Janeiro, também publicado em formato de livro no mesmo ano, em 1857. O romance se inicia no começo do século XVII, mais

\footnotetext{
${ }^{1}$ Doutorando em Espanhol, Texas Tech University, Lubbock, Texas, E.U.A- E-mail: gustavo.costa@ttu.edu
} 
precisamente no ano de 1604, tendo como cenário a casa do português Dom Antonio de Mariz, que teria participado da fundação da cidade do Rio de Janeiro em 1567. Sua família vivia à beira do Rio Paquequer, na Serra dos Órgãos, no Rio de Janeiro, ali viviam também cavaleiros e aventureiros que obedeciam às ordens do fidalgo português.

A história tem como personagens principais o índio Peri e a filha de Dom Antônio, Cecília, quando há o encontro entre estes dois grupos sociais: a portuguesa e a indígena. Peri é considerado um herói, já que o índio salvou Ceci da morte, pois ela seria morta pelos índios aimorés enquanto se banhava em um rio. O indígena, então, depois desse ato heroico, foi convidado pelo fidalgo português a estar próximo a eles, cuidando de sua filha, conquistando assim a amizade do pai e da filha. Não só defendeu Ceci dos perigos da floresta, como também de outro personagem da obra chamado Loredano, italiano, ex- frei cujo nome verdadeiro é Ângelo di Lucca, que tinha a intenção de não só destruir a família portuguesa, mas também de sequestrar Cecília e torná-la sua.

Primeiramente, serão abordados alguns fatos históricos que diz respeito à religião católica trazida pelos portugueses ao Brasil no século XVI e como era este cenário religioso na América portuguesa, ora entre os colonos ora entre os indígenas que nestas terras viviam. $\mathrm{Na}$ visão dos colonizadores europeus, os indígenas eram considerados selvagens e poderiam ser apontados como animais, logo, exterminados pelo homem branco, sendo seres humanos suscetíveis à salvação pela fé cristã de Deus o salvador. De acordo com um trecho da carta do Padre Manuel de Nóbrega, os jesuítas ${ }^{2}$ acreditavam na necessidade de converter os índios em cristãos, tornando-os submissos, portanto, reagiam à dessemelhança representada por essas "criaturas" da seguinte maneira

A lei que lhes hão de dar, é defender-lhes comer carne humana e guerrear sem licença do governador; fazer-lhes ter uma só mulher, vestirem-se, pois tem muito algodão, ao menos depois de cristãos, tirarlhes os feiticeiros, mantê-los em justiça entre si e para com os cristãos, fazê-los viver quietos sem se mudarem para outra parte, se não for para entre os cristãos, tendo terras repartidas que lhes bastem, e com estes Padres da Companhia para os doutrinarem (ALENCAR, 1999, p. 450).

Assim sendo, ter controle absoluto sob esses nativos era essencial, obrigando-os a seguir as "leis" cristãs que lhes eram impostas. Quando se menciona acima sobre o corpo do indígena, o qual deveria ser coberto, é citada a religião para sustentar a ideia de doutrina,

${ }^{2}$ Membro da Companhia de Jesus, fundada por Santo Inácio de Loiola (Dicio, Acesso em: 12 mar. 2016.) 
respeito e ordem, algo que os indígenas não conheciam, razão esta por andarem nus, podendo ser extinta pelas medidas jesuíticas, obedecendo à ordem portuguesa.

Os gentios, de acordo com o Estado Português, serviam para os trabalhos braçais e para a proteção dos colonos, mesmo que fossem sido convertidos ao cristianismo, eram considerados diferentes dos portugueses. A desobediência dos índios tinha consequências, de acordo com os portugueses: os gentios não teriam a salvação, por conseguencia, os colonos "usavam" os índios como soldados contra os inimigos que buscavam a ocupação de seu território. Os portugueses notaram os obstáculos em relação ao convívio com os índios, estes que eram alheios à cultura dos colonos. Para os recém chegados a estas terras, a religião e a crença em Deus estava acima de tudo, o ser humano existia porque Deus é o criador, sendo a obediência a Ele um ato inevitável. Segundo José Maria de Paiva (2005, p. 5, apud NÓBREGA, 2000, p. 221)

Como não sabem que coisa é crer nem adorar, não podem entender a pregação do Evangelho, pois ela se funda em fazer crer e adorar a um só Deus e a esse só servir; e como este gentio não adora nada, nem crê nada, tudo o que lhe dizeis se fica em nada.

Entretanto, sabe-se que existia indígenas que jamais escutaram falar sobre Deus, sua crença era na natureza e no que esta lhes oferecia. Isso fez com que muitos colonos fossem se mesclando com os costumes indígenas provindos da natureza

Os colonos não experimentavam apenas o afastamento do culto divino, o afastamento da obediência aos preceitos, mas muito mais, experimentavam a possibilidade de não serem cristãos e, por extensão, a possibilidade de não serem portugueses (JOSÉ MARIA DE PAIVA, 2005, p. 11).

$\mathrm{Na}$ América portuguesa havia a o sincretismo religioso devido às crenças indígenas e africanas que se introduziam à casa dos senhores da época. Os indígenas possuíam suas crenças e faziam seus rituais, sendo o Pajé a figura principal no mundo indígena, estes idolatravam o sol e a lua, consideravam que depois da morte, viveriam em um plano além das montanhas longínquas, um universo onde não existia o mal, onde os finados se reencontravam com seus antepassados. Os sacerdotes e a elite branca da época se empenhavam em não aceitar nenhuma atividade desse povo que não era católico, assim sendo, as orações católicas eram tidas pelos colonizadores como salvadoras de todo o mal que neste ambiente estava presente 
Enquanto a figura do indígena ganhava ares europeus, retomando uma idéia de Platão de que existira uma ilha esplêndida, Atlante, terra de valorosos homens e exemplar cultura que tinha se colocado agora, sob o domínio indígena, ou seja, aqueles povos ainda poderiam encontrar a salvação, para muitos religiosos, porque descendiam de antigos troncos europeus. (FREIRE; APOLINÁRIO, 2008, p. 6).

Os indígenas, no século XVII, aderiram a alguns costumes católicos, a chamada Santidade, cujo principal objetivo era a reverência a uma figura de pedra, além de que esses indígenas começaram a estabelecer seus rituais em templos, sendo que anteriormente esses cultos eram feitos a céu aberto. A igreja católica na colônia era representada por bispos, frades e padres, portanto, as práticas rotineiras dos que nesse espaço viviam se diferenciavam umas das outras, não obedecendo integralmente o que lhes era imposto pela religião romana. A possível similaridade entre as classes sociais da época em relação à religião católica se dava por meio de valores primordiais como atos de promessas, associação com santos e práticas religiosas que levavam os indigenas ao culto de adoração, tendo como alguns ícones sagrados esses mesmos santos, a Nossa Senhora e a Santa Cruz, encontrados nas casas, igrejas e nas margens de estradas. Abaixo, encontra-se um trecho da obra de Alencar que evidencia a presença de imagens de santos na casa de Dom Antonio de Mariz na fala do personagem Loredano

-Que tem? Os santos, as sagradas imagens bentas não são coisas que se atire ao chão! Se tão danada tentação nos tomasse, pediríamos a Deus que nos livrasse dela [...] / -Tendes medo de tocar nos santos, disse Loredano avançando para eles; pois bem, serei eu que deitarei a parede abaixo. Continuai, e avisai-me quando for tempo (ALENCAR, 1999, p. 313).

Na obra de Alencar, Peri, um índio Goitacá ${ }^{3}$, se resignou à religião do conquistador, papel desempenhado por Ceci e sua família, sendo a "senhora" o motivo de conversão do indígena ao cristianismo. O início dessa futura conversão ao catolicismo ocorreu quando o índio presenciou a imagem de Nossa Senhora

A pobre mãe recebeu esta palavra como uma sentença irrevogável; sabia do império que exercia sobre a alma de Peri a imagem de Nossa Senhora, que ele tinha visto no meio de um combate e havia personificado em Cecília (1999, p. 141).

\footnotetext{
${ }^{3}$ Indivíduo dos goitacás, grupo indígena do Brasil, hoje extinto, e que no séc. XVI habitava as terras próximas do litoral do Espírito Santo até o vale do rio Paraíba (Dicio: Acesso em: 12 mar. 2016).
} 
Em seu ambiente natural o índio teve essa visão cristã, que pode ser também relacionada à natureza onde vivia, ou seja, a este âmbito de pureza que lhe proporcionava força e coragem para lutar contra os inimigos da selva e consequentemente aos traços de Cecília, loira, de olhos azuis que refletiam o céu e sua pele clara. Assim sendo, a imagem de Nossa Senhora lhe serviu, em uma visão católica, a se converter a essa fé para seguir ao lado de sua senhora Cecília, protegendo-a dos perigos que lhe rondavam. Isso somente foi possível pelo fato de Peri ter aspirado muito por esta conversão, sendo aceita por Dom Antônio de Mariz. Logo, para que pudesse salvá-la e para que o pai da moça permitisse que o índio a levasse ao Rio de Janeiro, no momento em que os índios Aimorés ${ }^{4}$ estavam atacando a fortaleza do português, Peri foi convertido ao catolicismo:

- Peri quer ser cristão! exclamou ele. D. Antônio lançou-lhe um olhar úmido de reconhecimento. / - A nossa religião permite, disse o fidalgo, que na hora extrema todo o homem possa dar o batismo. Nós estamos com o pé sobre o túmulo. Ajoelha, Peri! O índio caiu aos pés do velho cavalheiro, que impôs-lhe as mãos sobre a cabeça./ - Sê cristão! Dou-te o meu nome. Peri beijou a cruz da espada que o fidalgo lhe apresentou, e ergueu-se altivo e sobranceiro, pronto a afrontar todos os perigos para salvar sua senhora. $(1999$, p. 366$)$

Ao se converter ao catolicismo, Peri deixou de ser àquele selvagem que poderia ameaçar a família portuguesa. O personagem Dom Antônio de Mariz fez a seguinte observação sobre o indígena quando falava com o cavalheiro Álvaro "Desde o primeiro dia que aqui entrou, salvando minha filha, a sua vida tem sido um só ato de abnegação. Crede-me Álvaro, é um cavalheiro português no corpo de um selvagem!” (1999, p. 56). Portanto, percebe-se que o personagem português julgava Peri como tendo a alma nobre portuguesa, entretanto, em seu ponto de vista, o indígena continuava tendo o corpo de um bárbaro. Houve, quiçá, nesta conversão do indígena, um sistema de etnocídio ${ }^{5}$ ?

O fato de Peri ter se convertido ao cristianismo por amor à sua senhora Ceci pode ser tratado, efetivamente, como uma forma de etnocídio, dado que o personagem Dom Antônio de Mariz aceitou que ele cuidasse de sua filha somente após a conversão. Cabe mencionar também aspectos de etnocídio praticados pelo próprio Peri, que renunciou à sua tribo, não retornou às

\footnotetext{
${ }^{4}$ Indígena da tribo dos aimorés: índios botocudos, aguerridos, que ocupavam, nos séc. XVI e XVII, extensões do território hoje compreendido pelos Estados da Bahia e do Espírito Santo. (Usa-se adjetivamente: a nação aimoré.) (Dicio: Acesso em: 12 mar. 2016).

${ }^{5}$ Destruição de uma etnia no plano cultural. (Dicio: Acesso em: 12 mar. 2016).
} 
suas raízes mesmo por meio de um pedido de sua mãe, aprendendo a língua portuguesa para se comunicar com os portugueses, falando o idioma ao decorrer da obra, deixando sua língua tupi de lado. Consequentemente, Peri aceitou o cristianismo, mesmo tendo que deixar seu passado de lado. A família de Dom Antônio de Mariz aceitou Peri como cristão, porém, admitindo indiretamente a não aceitação de sua origem selvagem em relação à "falta" de religião do indígena, na visão dos portugueses. A família seguia indiscutivelmente as leis católicas. Os argumentos para convencer o indígena à conversão ao cristianismo eram a necessidade de redenção de seu espírito para não somente conhecer a Deus, mas também que pudesse estar mais próximo à família, no seu dia-a-dia. A gratidão que Cecília sentia por Peri era enorme, e sentia que seria mais fácil se Peri se convertesse para que sua mãe e os outros que rodeavam a família aceitassem o indígena a tê-lo como amigo, sem que houvesse dúvidas de suas boas ações

Educada no fervor religioso de sua mãe, embora sem os prejuízos que a razão de D. Antônio corrigira no espírito de sua filha, Cecília tinha a fé cristã em toda a pureza e santidade. Por isso se afligia com a idéia de que Peri, a quem votava uma amizade profunda, não salvasse a sua alma, e não conhecesse o Deus bom e compassivo a quem ela dirigia suas preces. $(1999$, p. $224 ; 225)$

Engana-se, pois, aqueles que pensavam que Peri aceitou a conversão ao catolicismo facilmente. Isso aconteceu em um momento de perigo, momento este em que não tinha escolha, senão converter-se para salvar sua querida Ceci. Anteriormente, Cecília já lhe havia pedido que se convertesse, porém, o indígena não aceitou, já que segundo ele

- Peri, selvagem, é o primeiro dos seus; só tem uma lei, uma religião, é sua senhora; Peri, cristão, será o último dos teus; será um escravo, e não poderá defender-te [...] / - Se Peri fosse cristão, e um homem quisesse te ofender, ele não poderia matá-lo, porque o teu Deus manda que um homem não mate o outro. Peri selvagem não respeita ninguém; quem ofende sua senhora é seu inimigo, e, morre! [...] / - Peri te desobedeceu por ti somente; quando já não corres perigo, ele virá ajoelhar a teus pés, e beijar a cruz que tu lhe deste. Não fica zangada! (1999, p. 226) 


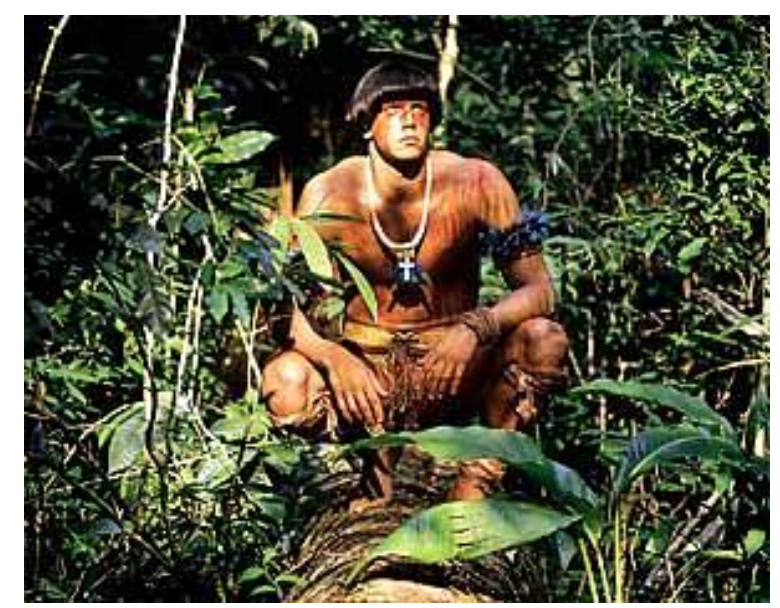

Cena do filme $O$ Guarani produzido em 1996 e dirigido por Norma Bengell no qual Peri está em seu ambiente natural, a floresta. ${ }^{6}$

Portanto, pode-se dizer que Peri amava os seus, entretanto, amava também sua senhora, e tinha uma árdua escolha a fazer. Cecília, entretanto, não correspondia a esse amor, pois o amor que sentia pelo indígena era de gratidão, ou até mesmo fraterno, neste último caso principalmente quando se interou de que o indígena já era cristão “-Tu és cristão, Peri?... exclamou a menina, cujos olhos brilharam com uma alegria inefável. - Sim; teu pai disse: "Peri, tu és cristão; dou-te o meu nome!"'- Obrigado, meu Deus, disse a menina juntando as mãos e erguendo os olhos ao céu" (1999, p. 375).

A situação fora da residência de D. Antônio de Mariz era arriscada, a qualquer momento os índios Aimorés conseguiriam invadir a casa. $\mathrm{O}$ fato de Peri ter se tornado cristão o mais rápido possível possibilitou sua partida com Cecília, e assim o fez. Cecília dormia, o índio cuidou dela no trajeto rumo ao Rio de Janeiro, confessando-lhe a razão pela qual aceitou ser cristão, já que o que mais queria Ceci era que o indígena vivesse junto a ela e o irmão na capital, entre os brancos. No seguinte diálogo entre a bela moça e o índio se tem as justificativas do indígena:

- Peri é um selvagem, disse o índio tristemente; não podendo viver na taba dos brancos". / - Por quê? Perguntou a menina com ansiedade. Não és tu cristão como Ceci? / - Sim; porque era preciso ser cristão para te salvar; mas Peri morrerá selvagem como Arerê. / - Oh! Não, disse a menina, eu te ensinarei a conhecer a Deus. Nossa Senhora, as suas

${ }^{6}$ O GUARANI. 2010. Disponível em: http://www.historiadocinemabrasileiro.com.br/o-guarani/foto-o-guarani/. Acesso em: 25 abr. 2016. 
virgens e os seus anjinhos. Tu viverás comigo e não me deixarás nunca" (1999, p. 386)

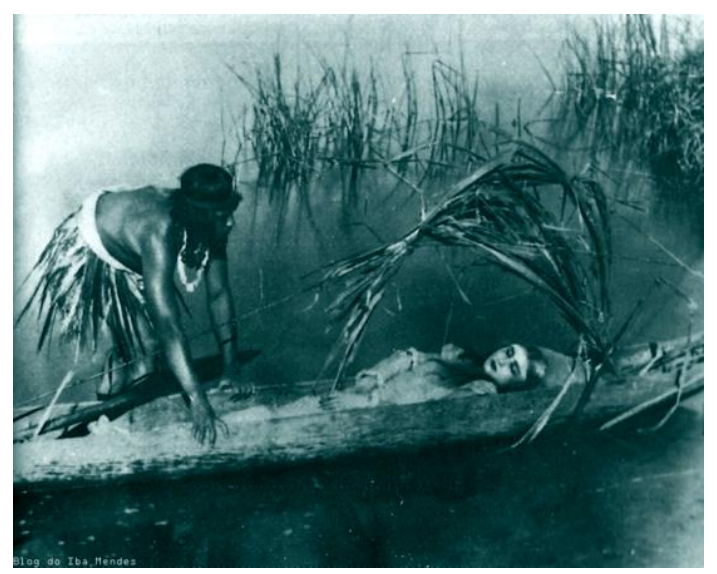

Cena do filme $O$ Guarani produzido em 1920 por João de Deus em que Peri leva Cecília ao Rio de Janeiro pelo rio $^{7}$.

Peri havia aceitado de coração a conversão cristã? De acordo com o trecho acima, não. Só o fez porque era a única maneira de levá-la dali. Se não se convertesse, o pai da moça não permitiria tal feito e Cecília acabaria morrendo junto aos demais integrantes da família.

Por conseguiente, a "farsa" na conversão de Peri pode ser considerada uma estratégia para o próprio bem de sua senhora. A partir de então, após deixar o lar destruído pelos Aimorés, se aventuraram inevitavelmente pelo rio em direção ao lugar de destino, onde Cecí reencontraria o irmão e parentes. No caminho, incidentes ocorreram e uma tempestade fez com que a floresta se inundasse e ambos tiveram que subir ao alto de uma palmeira esperando que o dilúvio acabasse, neste momento, no entanto, a história termina. Salvaram-se? Morreram? Alencar deixa o final em aberto e o leitor é levado a interpretar o destino de ambos os personagens.

Pode-se subentender, contudo, que a raça brasileira poderia ter se iniciado desde então, ou seja, da salvação dos personagens e a união carnal entre eles, nascendo herdeiros na mistura da raça portuguesa com a indígena, dando origem a etnia brasileira.

Concluindo, o fato de que o indígena tenha visto a imagem de Nossa Senhora em uma batalha e prontamente ter feito sua conversão ao cristianismo proporciona uma imagem de “aceitação" desta religião por parte de Peri, no entanto, ao comentar à Ceci que não viveria com

\footnotetext{
${ }^{7}$ Por que tantas versões de O Guarani? 2013. Disponível em: http://www.ibamendes.com/2011/12/por-quetantas-versoes-de-o-guarani.html. Acesso em: 25 abr. 2016.
} 
ela entre os brancos e que "morrerá selvagem como Arerê" (1999, p. 386) o indígena acaba confessando realmente a não aceitação da sua conversão, podendo-se, portanto, considerar esta como uma "falsa aceitação". O que é aceito de fato na obra são as circunstâncias que levam as duas partes a tomarem certas decisões com o objetivo de salvar à vida alheia e, igualmente, a relação de confiança e amizade entre estas distintas etnias.

\section{Referências bibliográficas}

ALENCAR, José de. O guarani. São Paulo: Klick Editora, 1999.

CHAHON, Sérgio. Visões da religiosidade católica no Brasil colonial. Revista Digital Simonsen, Rio de Janeiro, v. 1, n. 1, p.85-99, 2014. Disponível em: <http://www.simonsen.br/revista-digital/wp-content/uploads/2014/12/Revista-

Simonsen_N1_Sergio-Chahon.pdf>. Acesso em: 01 mar. 2016.

DICIO. Disponível em: 〈http://www.dicio.com.br/>. Acesso em: 12 mar. 2016.

FREIRE, Gláucia de Souza; APOLINÁRIO, Juciene Ricarte. Do viver ao praticar: Sincretismo religioso no Brasil colonial. Mneme - Revista de Humanidades, Caicó, v. 24, n. 9, p.1-13, 2008. Disponível em: <http://www.cerescaico.ufrn.br/mneme/anais>. Acesso em: 12 mar. 2016.

JOSÉ MARIA DE PAIVA, 9., 2005, Ponta Grossa. A doutrina feita aos índios: Brasil, século XVI. Ponta Grossa: 2005. 12 p. Disponível em: <http://www.pg.utfpr.edu.br/ppgep/Ebook/cd_Simposio/artigos/mesa_redonda/art8.pdf>. Acesso em: 15 mar. 2016.

NÓBREGA, Pe. Manuel da, S. J. Cartas da Baia, 8/5/1558. In: Leite, Serafim S. J. (Org). Cartas dos primeiros jesuítas do Brasil: Monumenta Brasilae, 1538-1563. Coimbra: Comissão do IV Centenário da Cidade de São Paulo / Tip. Da Atlântida, 1954. V.2, p. 450.

OLIVEIRA, Ellen dos Santos; QUINTELA Vilma Mota. Indicius de Etnocídio em "O Guarani”, de José de Alencar. In: V Mostra de Inscrição Cientifica. Sergipe: FSLF. 2012. Disponível em: http://www.fslf.com.br/images/stories/PDF/5MC/anais_eletronicos.pdf SILVEIRA, Éder. TUPI OR NOT TUPI: Nação e nacionalidade em José De Alencar e Oswald de Andrade. 251 f. Tese (Doutorado) - Curso de História, Instituto de Filosofia e Ciências Humanas, Universidade Federal do Rio Grande do Sul, Porto Alegre, 2007. 
Revista de Estudos Acadêmicos de Letras

VAINFAS, Ronaldo. A Heresia dos Índios: Catolicismo e rebeldia no Brasil colonial. São Paulo: Companhia das Letras, 1995. 